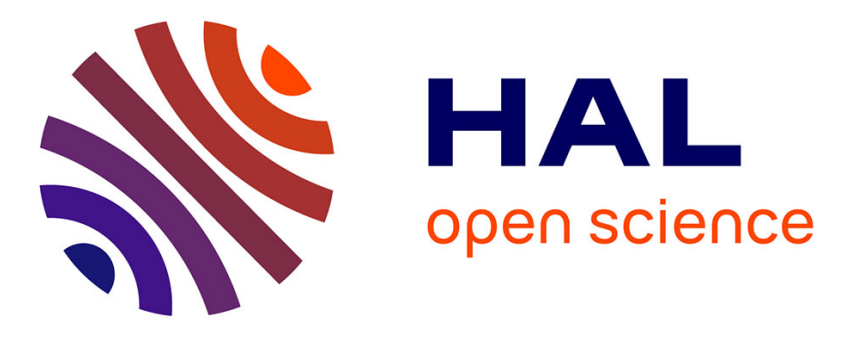

\title{
Advanced 56 channels stimulation system to drive intrafascicular electrodes
}

Thomas Guiho, David Andreu, Victor Manuel López-Alvarez, Paul Cvancara, Arthur Hiairrassary, Loïc Wauters, Giuseppe Granata, Winnie Jensen, Jean-Louis Divoux, Silvestro Micera, et al.

\section{To cite this version:}

Thomas Guiho, David Andreu, Victor Manuel López-Alvarez, Paul Cvancara, Arthur Hiairrassary, et al.. Advanced 56 channels stimulation system to drive intrafascicular electrodes. ICNR: International Conference on NeuroRehabilitation, Oct 2016, Segovia, Spain. pp.743-747, 10.1007/978-3-319-466699_122. lirmm-01386618

\section{HAL Id: lirmm-01386618 https://hal-lirmm.ccsd.cnrs.fr/lirmm-01386618}

Submitted on 24 Oct 2016

HAL is a multi-disciplinary open access archive for the deposit and dissemination of scientific research documents, whether they are published or not. The documents may come from teaching and research institutions in France or abroad, or from public or private research centers.
L'archive ouverte pluridisciplinaire HAL, est destinée au dépôt et à la diffusion de documents scientifiques de niveau recherche, publiés ou non, émanant des établissements d'enseignement et de recherche français ou étrangers, des laboratoires publics ou privés. 


\title{
Advanced 56 channels stimulation system to drive intrafascicular electrodes
}

\author{
T. Guiho ${ }^{1}$, D. Andreu ${ }^{1}$, V. M. López-Alvarez ${ }^{3}$, P. Cvancara $^{4}$, A. Hiairrassary, G. Granata ${ }^{7}$, L.

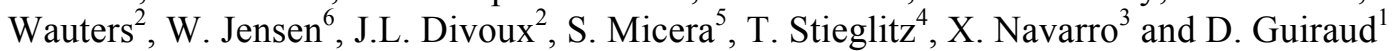

\begin{abstract}
A wearable, 56-channel stimulator was developed and successfully tested to drive multichannel intrafascicular electrodes. It is able to safely elicit sensory afferent signals through the activation of 4 Time- $4 \mathrm{H}$ intrafascicular electrodes. The STIMEP embeds not only the pulse generator but also a software that ensures: i) real time control by a hand-prosthesis, ii) embedded procedures for sensation mapping interfaced with a PC software, iii) impedance follow-up, iv) real-time safety management.
\end{abstract}

\section{INTRODUCTION}

W ITHIN the project EPIONE, our aim was to develop a prototype system to apply multi-channel microstimulation to the nerve stump of an amputee volunteer to manipulate his phantom limb sensations, and explore the possibility of using the method as a treatment for PLP.

The key technological challenges in this project involved the development of a portable multi-channel stimulator, a multi-channel peripheral nerve interface (i.e. the TIME-4H electrode) to be interfaced either with a psychophysical testing platform to evaluate the sensations generated or a handprosthesis to feedback sensations. The technological developments was guided, validated and evaluated through simulation studies and animal experiments.

\section{MATERIALS}

Electrical stimulation of nerves is provided to the implanted transverse intrafascicular multichannel electrodes (TIME-4H) by the dedicated STIMEP neurostimulator able to address up to 56 different stimulation contacts and 8 ground electrodes. For therapy, STIMEP is remotely controlled in two different modes:

i) Direct therapy parameterized by the Psychophysical Testing Platform (HMI software on PC) through insulated USB link.

This work is conducted by the EU project 'EPIONE' under the FP7 Health program (HEALTH-F2-2013-602547), www.project-epione.eu.

1 Univ. of Montpellier, France

2 Axonic, MXM group, Sophia Antipolis, France

3 Univ. Autonoma of Barcelona, Spain

4 Univ. of Freiburg, Germany

5 EFPL, Lausanne, Switzerland

6 Univ. of Aalborg, Denmark

7 Universita’ Cattolica del Sacro Cuore, Roma, Italy ii) Stimulation of sensory feedback in grasping tasks through insulated SPI controlled in real time by pressure and position sensors placed on a hand-prosthesis worn by the patient. This induces a bidirectional relationship between the patient and the hand-prosthesis.

The main features of STIMEP are reported in table 1 and the architecture is schematically represented on Fig. 1. It consists of: i) a controller (SOC device) exchanging data with $\mathrm{PC}$ or the hand prosthesis, ii) 4 insulated stimulation units able to drive 4 TIME-4H simultaneously and independently. Each stimulation units is composed of CAFE24: proprietary analog ASIC stimulation front-end and a proprietary digital architecture based on an FPGA embedding communication functions, control of stimulation profiles and safety monitoring by means of reference models. A SOC-based controller drives and coordinates the 4 stimulation module activities each connected to a TIME-4H electrode. To comply with human trials, a full set of documentation, as per ISO 13485,conception, IEC 62304 for software part and 93/42/EEC directive (definitions, designs, protocols, justifications, flow charts, etc.), together with various regulatory files, including risk analysis, have been provided and are available for national authorities.

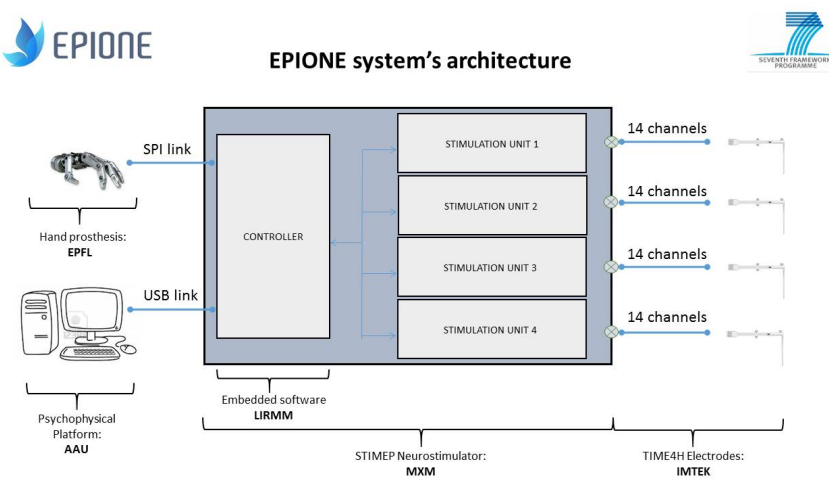

Figure 1 STIMEP global architecture with partners' contribution.

Achievements:

- Specification of the XML-based application protocol on the USB/SPI link, implementation on the embedded processor of the XML parser.

- Development of the 5 embedded Epione procedures configured by the Psychoplatform (impedance fast check, threshold search, therapy, sensation characterization) 
- Development of the SYNERGY Neurostimulation software (accurate impedance check, system check, logged data upload).

- All the procedures were formally modeled (Petri nets), analyzed and tested once implemented on $\mu \mathrm{COS}$ certified real-time Operating System using $C$ language.

- Smart synchro out configuration for system checking, SEP and other measurements.

- Safety procedures were designed, implemented and tested (USB communication watchdog, CRC, XML parser with frame decoding and checking), locked (forbidden) outputs management, charge injection limits (both to avoid patient pain and electrode corrosion).

- Log of relevant information both at user level (the psychoplatform or SYNERGY Neurostimulation software) and at technical level.

- Complex algorithms, for Handprosthesis control only, of frequency, Intensity and pulse width modulation (real time control of stimulation parameters linked to sensory feedback).

The application protocol on the SPI link for real time control allows to control simultaneously up to 8 active contacts playing independently with intensity and pulsewidth.

\section{RESULTS}

The whole system was first successfully tested on animals with implanted TIME-4H electrodes. On rats at UAB, sciatic nerve was implanted and EMG of 3-targeted muscles were recorded - i.e. tibialis anterior (TA), gastrocnemius (GM) and plantar interossei (PL) - and showed that the stimulation is accurately delivered to the different fascicules through selective recruitments. STIMEP performance was especially tested in studies designed to assess impact of pulse widths and intensities variations on recruitment (Fig. 2). Pigs experiments at AAU showed that the whole software and hardware was completely safe and that on a bigger nerve closed to the size of the targeted human ones, the same level of selectivity was achievable. These experiments validated all software routines used in human clinical trials. Both experiments will be shortly presented together with unpublished first human data.

\section{CONCLUSION}

As far as we know, this is the first system allowed for invasive human's trial able to drive simultaneously 4 multicontact intrafascicular electrodes. The system enables real-time control of intensity, pulse-width and frequency of the stimulation to elicit very accurate sensation feedback. It also embeds impedance checking while being small enough to be further integrated in a future implantable pulse generator. The system is currently successfully used in a first human trial. Besides, the technology allows very advanced stimulation paradigms that may be explored in the future.

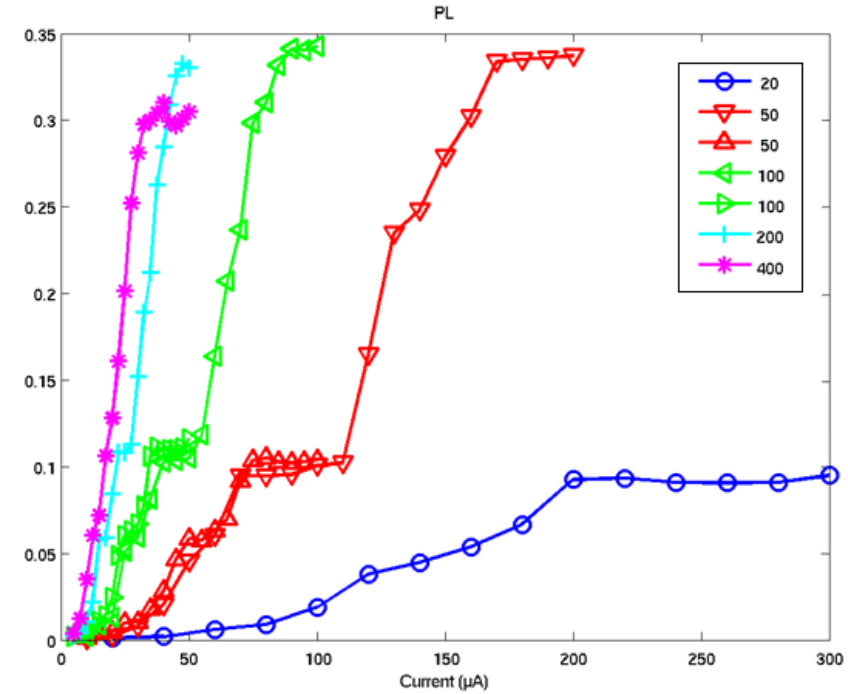

Fig. 2. Recruitment curves for several PW (20 to $400 \mu \mathrm{s}$ ) and I (20 to $300 \mu \mathrm{A}$ with à $20 \mu \mathrm{A}$ step) for PL muscle. It should be noted that 2 different index are used both for 50 and $100 \mu \mathrm{s}$. This is due to additional point linked to a stimulation pitch decrease between 2 I. $x$-axis presents stimulation intensities while y-axis is expressed in Volt-RMS and presents average values over 5 repetitions.

\section{ACKNOWLEDGMENT}

The EPIONE consortium includes the following partners; 1) W. Jensen, Aalborg University, Denmark (project coordinator), 2) P. Sørensen, Aalborg University Hospital, Denmark, 3) P. M. Rossini, Universita' Cattolica del Sacro Cuore, Italy, 4) R. Wassim \& A. Laurent-Applegate, Centre Hospitalier Universitaire Vaudois, Switzerland, 5) T. Stieglitz, Albert Ludwigs Universität Freiburg, Germany, 6) D. Guiraud, Laboratoire d'Informatique de Robotique et de Microelectronique de Montpellier, France, 7) S. Micera, École polytechnique fédérale de Lausanne, Switzerland, 8) F. Sebelius, Lund University, Sweden, 9). K. Yoshida, Indiana University-Purdue University Indianapolis, USA, 10). X. Navarro, Universitat Autonoma de Barcelona, Spain, 11) J. Tilly, Novosense AB, Sweden, 12) JL Divoux, Axonic, France.

\section{REFERENCES}

[1] H. Leroux, D. Andreu, K. Godary-Dejean. Petri nets based digital architecture: from formalism to implementation on FPGAs. IEEE Transactions on Industrial Informatics, Vol. 11, N. 4, 2015.

[2] P. Maciejasz, J. Badia, T. Boretius, D. Andreu, T. Stieglitz, W. Jensen, X. Navarro, D. Guiraud. Delaying discharge after the stimulus significantly decreases muscle activation thresholds with small impact on the selectivity - An in vivo study using TIME electrode. Medical \& Biological Engineering \& Computing, 53(4), 371-9, 2015.

[3] J. Badia, T. Boretius, D. Andreu, C. Azevedo Coste, T. Stieglitz, X Navarro. Comparative Analysis of Transverse Intrafascicular Multichannel Electrode (TIME), Longitudinal Intrafascicular Electrode (LIFE) and Multipolar Cuff Electrode for the Selective Stimulation of Nerve Fascicles, Journal of Neural Engineering, 8 (3), 2011.

[4] D. Andreu, D. Guiraud, G. Souquet. A Distributed Architecture for Activating the Peripheral Nervous System. Journal of Neural Engineering, 6, 2009. 